\title{
Advances in managing pelvic floor disorders
}

\section{Joan Pitkin}

Address: Northwick Park \& St Marks Hospital, Northwest London Hospitals NHS Trust, Watford Road, Harrow, Middlesex, HA1 3UJ, UK

Email: pitters@ukusers.net

FI000 Medicine Reports 2009, I:87 (doi:10.3410/MI-87)

The electronic version of this article is the complete one and can be found at: http://FI000.com/Reports/Medicine/content///87

\begin{abstract}
The last 10-12 years have seen an avalanche of changes in both the management of incontinence and genital prolapse. So many new procedures continue to appear that often the clinician is confused as to which approach to adopt. Complications are now being reported, creating a need to reappraise the situation.
\end{abstract}

\section{Introduction and context}

Previously, anterior vaginal repair and colposuspension were the main available procedures to combat incontinence, however, the former was largely discredited for having a low 5-year dry rate [1] (although dry rate is difficult to define and may vary according to the perspective of the clinician or the patient). A number of needle suspension procedures (for example, Stamey or $\mathrm{Raz}$ ) were popular for a while but also had poor dry rates. Suburethral autologous slings are not new; the use of the gracilis muscle was described in 1907. Since then, modifications have used other muscles such as pyramidalis, rectus fascia, and fascia lata. Traditionally, this was considered an operation for patients who remained incontinent despite previous bladder neck surgery. If the operation is performed as a primary procedure, a $90 \%$ success rate is quoted, but like colposuspension, the procedure carries significant complications, with a de novo detrusor instability rate of around $16 \%$ and a postoperative voiding disorder rate of $10 \%$.

Currently, there is a wide range of approaches for restoring continence, ranging from injectables (bulking agents) to midurethral slings. These may be retropubic midurethral slings, for example, tension-free vaginal tape (TVT) or transobturator midurethral sling (TOT) procedures. The latter may be introduced by an outside-in or an inside-out technique, and there are numerous varieties of tape to apply, with differing pore size and tensile strength confounding the comparison of data between clinical series.

Pelvic organ prolapse (POP) has classically been treated with standard surgical approaches, using midline plication for anterior and posterior compartmental defects and either abdominal or laparoscopic sacrocolpopexy or sacrospinus fixation for apical prolapse. Magnetic resonance imaging $[2,3]$ has contributed to the understanding of anatomical defects so that lateral defects along the line of the arcus tendinious can now be detected, altering the approach to repairs in some cases. Synthetic meshes and biological grafts have been introduced along with numerous materials and implementation procedures, but their use has not been backed up by robust randomised controlled trial (RCT) data. Research into the use of synthetic meshes often takes the form of small observational or retrospective studies or case series, often with a short follow-up and numerous confounding variables.

Long-term data are essential for any technique as initial promising results may be misleading. A classical example of this is NASHA-Dx (non-animal stabilised hyaluronic acid/dextranomer), or Zuidex ${ }^{\mathrm{TM}}$, used to treat stress incontinence. The initial multicentre study [4] demonstrated a $77 \%$ response rate at 12 months. However, reported cases of pseudocysts have appeared [5] and stress urinary incontinence (SUI) may return when the 
abscess is drained. A case of suburethral mass has been described [6]. Zuidex ${ }^{\mathrm{TM}}$ has now been withdrawn from the UK market.

\section{Recent advances}

\section{Stress urinary incontinence}

Cross-linked polydimethylsiloxane (Macroplastique ${ }^{\circledR}$ ) has been available since 1991 to treat urinary incontinence and is the European bulking agent leader. The first North American single-blinded multicentre study of crosslinked polydimethylsiloxane has just been published [7] with an intention-to-treat analysis. A total of 247 women with intrinsic sphincter deficiency were randomly assigned to receive Macroplastique ${ }^{\circledR}$ or Contigen ${ }^{\circledR}$, which served as a control. Repeat injection was allowed at 3-month follow-up. Effectiveness was determined at 12 months using assessment of leakage by Stamey grade, 1-hour pad test, and urinary incontinence quality-of-life (QoL) scale scores. Many of these women had been incontinent for a long time (average of 11.2 years), and $24 \%$ had undergone prior incontinence surgery. At 12 months, $61.5 \%$ of the Macroplastique ${ }^{\circledR}$ patients and $48 \%$ of the Contigen ${ }^{\circledR}$ controls had improved by 1 Stamey grade. The total dry rates were $36.9 \%$ for Macroplastique ${ }^{\circledR}$ patients and $24.8 \%$ for controls $(P<0.05)$. QoL score changes in the two groups were similar. A 2-year extension study is ongoing. This study, providing larger numbers, supports the favourable small-cohort 5-year follow-up data on Macroplastique ${ }^{\circledR}[8,9]$, which also demonstrated minimal complications.

Midurethral sling procedures are now commonplace, with 10- to 11-year follow-up data available for TVTs. Data from the Austrian Registry are now available for the TOT procedure as well [10] and contain data on 2,543 operations with 11 different tape systems. Intra-operative complications occurred in $4.7 \%$ of cases, including bleeding and 2 urethral, 10 bladder, and 10 vaginal perforations. Re-operations (including 24 tapes cut or loosened) were needed for 57 women, of whom 11 had vaginal erosions. There was one retropubic haematoma. Bladder perforation occurred more often with outside-in than inside-out techniques. Data on incontinence surgery extracted from the Danish National Patient Register revealed an incomplete registration of complications and re-operations, especially in the TVT group [11], and highlighted the need for data that are more transparent and robust.

So-called 'needleless' tapes and 'minislings' are now being introduced for SUI. These are smaller than conventional tapes and can be inserted in the outpatient setting under local anaesthesia. Data are limited but a randomised trial comparing TVT with the MiniArc ${ }^{\mathrm{TM}}$ (American Medical Systems) showed significantly less satisfactory results in the latter group, both objectively and subjectively, at 6 months [12]. It has been postulated that this tape is too short to obtain adequate fixation. A randomised trial of a TVT-obturator (TVT-O ${ }^{\circledR}$; Gynecare) versus the Contasure Needleless ${ }^{\circledR}$ (Neomedic International) single incision tape, however, showed equivalent objective and subjective results at 1 year [13], with significantly more leg pain in the TVT-O ${ }^{\circledR}$ group. The NICE (National Institute for Health and Clinical Excellence) Interventional Procedure Guidance [14] quotes current evidence as inadequate and suggests that insertion of these devices should be confined to research studies or allowed only if data are entered onto a national register.

\section{Combining continence procedures and prolapse surgery}

Several groups have tried to rationalise the long-standing questions of whether to perform prophylactic continence procedures during POP corrective surgery and whether to embark on POP surgery when inserting midurethral tapes. The Netherlands TVT database showed good 2-year success rates when TVT was performed with concomitant prolapse surgery [15]. Fifty-nine women undergoing TVT and POP surgery were compared with 687 women having TVT alone. The IIQ-7 (Incontinence Impact Questionnaire) and the UDI-6 (Urogenital Distress Inventory) were used to evaluate outcomes. In this study, all of the women required continence procedures but only a few had coexisting prolapse. It is reassuring to know that the tape was equally successful whether inserted alone or in conjunction with a prolapse repair. The more vexing clinical question is whether prophylactic tapes should be inserted in patients who are undergoing prolapse surgery but who do not currently leak, to prevent occult incontinence from being unmasked. In this situation, a number of women will receive unnecessary surgery and may develop complications associated with tape insertion. The prediction of those who will develop postoperative incontinence is also problematic.

One study followed 1,356 women for 18 months (that is, 6 months pre-operatively to 1 year post-operatively) and found that $34.4 \%$ had undergone concomitant POP surgery (usually anterior repair) at the time of the tape insertion. The women who had received prolapse repairs were significantly less likely to develop a new prolapse or undergo repeat surgery for prolapse or surgery for SUI than those who had received tape alone. The latter group, however, had less bladder neck outlet obstruction and developed less urethral diverticulae [16].

Clinical algorithms are needed to guide the clinician on this matter; there have been four International Consultations on Incontinence (ICIs) that have developed 
algorithms for children, men, women, and neurogenic bladders. The recommendation is that, if stress incontinence surgery is required, coexisting prolapse should be corrected. In the fourth ICI, it was stated that no grade A recommendations could be given due to lack of evidence, and the optimal diagnostic algorithm and need for concomitant SUI surgery have yet to be determined [17]. One study attempted to provide this in relation to the insertion of midurethral tape at the time of POP repair [18]. Tapes were inserted only if there was urodynamically proven or occult SUI. In cases of clinical or no incontinence, no tape was inserted. In the group with tape insertion, there was an $8.5 \%$ risk of tape excision, cutting the tape, or urethrolysis. In the group with POP repair and no tape, there was an $8.3 \%$ risk of requiring a bladder neck procedure later; that is, the risk of obstructive difficulties post-sling was equal to the risk of persistent SUI post-operatively with no sling. Those patients with clinical incontinence, in whom tapes were withheld, were found to have a 30\% chance of requiring a continence procedure post-POP repair. This group was added to the algorithms to receive a midurethral tape at the time of the original surgery. The severity of SUI is an important parameter that influences results after TVT-O and TVT and could be used by surgeons in selecting the most effective intervention [19].

\section{Pelvic organ prolapse}

Surgery for POP is governed by a need to maintain painfree function and a desire to prevent recurrence (risk quoted at 15-25\%). Clinicians are divided on whether biografts are preferable to synthetic mesh, which can incur complications such as erosion and ridging, and whether additional support should be inserted only in re-do surgery or as first-line treatment.

A meta-analysis of 10 RCTs ( $n=1,087$ patients) using adjuvant materials versus standard surgery for anterior vaginal prolapse showed a lower objective recurrence rate at 1 year in those cases in which biological adjuvant material (odds ratio [OR] 0.56, 95\% confidence interval [CI] 0.34-0.92) and absorbable synthetic adjuvant material (OR 0.44, 95\% CI 0.21-0.89) were used [20].

A recent prospective study randomly assigned 190 women with recurrent symptomatic stage 2 (or greater) cystocele to receive either Gynemesh ${ }^{\circledR}$ (Ethicon, Inc.), a knitted, monofilament, large-pore polypropylene, non-absorbable mesh, or Pelvicol ${ }^{\circledR}$ (CR Bard, Inc.), a porcine dermis acellular graft [21]. All patients received full objective assessment, including POP-Q (POP-quantification) staging, urodynamics, P-QoL (Prolapse Quality of Life Questionnaire) and short form of PISQ-12 (Pelvic Organ Prolapse - Urinary Incontinence Sexual
Questionnaire). Ninety-six women, of whom 60 had previously undergone hysterectomy, were randomly assigned to Gynemesh ${ }^{\circledR}$, and 94, including 54 hysterectomised women, received Pelvicol ${ }^{\circledR}$. All patients completed a 2-year follow-up. Anterior vaginal wall recurrence was observed in $28.1 \%$ of the Gynemesh ${ }^{\circledR}$ group and $43.6 \%$ of the Pelvicol ${ }^{\circledR}$ group. This did not reach statistical significance $(P=0.06)$. None of the women with recurrence was symptomatic enough to require re-operation. Mesh erosions were encountered in six of the Gynemesh $^{\circledR}$ group (6.3\%) and in none of the Pelvicol ${ }^{\circledR}$ group $(P=0.02)$. All erosions were obvious by 6 months after surgery. Patients in the Pelvicol ${ }^{\circledR}$ group exhibited improvement in all but one of the QoL domains as compared with improvement in four domains with Gynemesh $^{\circledR}$. Sexuality was unchanged on PISQ-12 scores in the Gynemesh ${ }^{\circledR}$ but showed a significant improvement in the Pelvicol ${ }^{\circledR}$ group $(P=0.03)$. The authors commented that meticulous attention to haemostasis and avoidance of extensive dissection were required and might be the reason for the lack of erosions in the Pelvicol ${ }^{\circledR}$ group compared with results from other papers [22,23]. The high prevalence of hysterectomised women in the Gynemesh $^{\circledR}$ erosion group is concordant with other papers [24] that suggested that prior hysterectomy may be a factor contributing to this complication.

A prospective longitudinal study now offers 5-year follow-up data on anterior and posterior vaginal wall prolapse with Pelvicol ${ }^{\circledR}$ [25]. In all, 72 patients with 82 defects had objective cure rates of $81.6 \%$ for anterior defects and $86.4 \%$ for posterior defects. The failure rate was six times higher for concomitant anterior and posterior repairs. Complete replacement of the endopelvic fascia has a better outcome than using classical plication or plication augmentation repairs.

A number of studies have now reported on complications associated with mesh. A retrospective cohort study involving 329 women from two district general hospitals and two tertiary urogynaecology referral units reviewed the short-term outcomes and complications after various prolapse repair mesh devices (76\% Gynecare and 24\% American Medical Systems devices). Operative complications included bladder injury (1.6\%) and rectal injury (1.1\%), and two women had serious vascular injuries. Post-operative complications included buttock pain (5.2\%), vaginal erosion (10\%), one bladder erosion, and two serious infections $(0.7 \%)$, leading to necrotising fasciitis in one case [26]. Five percent of the women had persistent prolapse at 3 months. Concerns have been echoed in the MAUDE (Manufacturer and User Facility Device Experience Database) of the US Food and Drug Administration (FDA) [27]. 
A larger retrospective study involving 684 women at seven French centres raised similar concerns [28]. Even with a short follow-up of 6 months, there was a $33.6 \%$ 'late complications' rate, including granulomas or prosthetic expositions (11.3\%), relapse of prolapse $(6.9 \%)$, and $5.4 \%$ de novo SUI. Early post-surgical complications included abscesses $(0.29 \%)$, haematomas $(1.9 \%)$, two vesico-vaginal fistulae, and one recto-vaginal fistula. Multivariate analysis confirmed that prior hysterectomy or placing an isolated anterior prosthesis were risk factors. The FDA has now issued a warning regarding complications associated with mesh, citing reports from nine different manufacturers, involving over 1,000 people with severe complications [29]. A carefully conducted case series demonstrated mesh complications in 1 in 20 women [30], with little evidence to support advantage.

Sexual dysfunction is an area now being considered in greater depth. Ridging and contraction of mesh prostheses remain potential causes of dyspareunia in younger patients. In a retrospective analysis, 87 women undergoing infracoccygeal sacropexy for apical vaginal prolapse were followed up for a mean of 27 months [31]. Post-operative perineal pain occured in $10 \%$, dyschesia (difficulty or pain in defecating) in 5\%, and dyspareunia in $6 \%$ of cases. Contraction may be related to inadequate tissue in-growth into the mesh [32]. More recently, animal models have shown less contraction with atelcollagen-coated mesh [33].

\section{Implications for clinical practice}

The management of pelvic floor dysfunction is a rapidly changing field. The challenge is to provide minimal access techniques that reduce recurrence rates but without an increase in morbidity. Data that are more robust are required on the newer interventions with additional randomised trials, longer duration of follow-up, and clearer definitions of outcomes, using standardised assessment tools. Bowel, bladder, and sexual parameters need to be assessed as women are demanding quality of life following SUI and POP surgery and frequently remain sexually active for longer with modern hormonal interventions. Various risk factors that could lead to clinical algorithms to help the clinician to determine which procedure is right for the patient have now been identified. Surgical techniques need to be reviewed and taught by experienced practitioners aiming at adequate throughput. Personal practice should be audited. National and international databases are needed for pooled morbidity and outcome measures.

\section{Abbreviations}

CI, confidence interval; FDA, US Food and Drug Administration; ICI, International Consultation on
Incontinence; IIQ-7, Incontinence Impact Questionnaire; MAUDE, Manufacturer and User Facility Device Experience Database; NASHA-Dx, non-animal stabilised hyaluronic acid/dextranomer; NICE, National Institute for Health and Clinical Excellence; OR, odds ratio; PISQ12, short form of Pelvic Organ Prolapse - Urinary Incontinence Sexual Questionnaire; POP, pelvic organ prolapse; POP-Q, pelvic organ prolapse quantification; QoL, quality of life; RCT, randomised controlled trial; SUI, stress urinary incontinence; TOT, transobturator midurethral sling; TVT, tension-free vaginal tape; TVT-O, tension-free vaginal tape-obturator; UDI-6, Urogenital Distress Inventory.

\section{Competing interests}

The author declares that she has no competing interests.

\section{References}

I. Glazener CM, Cooper K: Anterior vaginal repair for urinary incontinence in women. Cochrane Database Syst Rev 2000, 2: CD001755.

2. Strohbehn K, Ellis JH, Strohbehn JA, DeLancey JO: Magnetic resonance imaging of the levator ani with anatomic correlation. Obstet Gynecol 1996, 87:277-85.

3. Chen L, Ashton-Miller JA, DeLancey JO: A 3D finite element model of anterior vaginal wall support to evaluate mechanisms underlying cystocele formation. J Biomech 2009, 42: I37I-7.

4. Chapple CR, Haab F, Cervigni M, Dannecker C, Fianu-Jonasson A, Sultan AH: An open, multicentre study of NASHA/Dx Gel (Zuidex) for the treatment of stress urinary incontinence. Eur Urol 2005, 48:488-94.

5. Loisel C, Secco M, Rocher-Barrat A, Caremel R, Grise P: [Periurethral pseudocysts following urethral injections of Zuidex: review of the literature] [article in French]. Prog Urol 2008, 18:1038-43.

6. Abdelwahab HA, Ghoniem GM: Obstructive suburethral mass after transurethral injection of dextranomer/hyaluronic acid copolymer. Int Urogynecol J Pelvic Floor Dysfunct 2007, I 8:1379-80.

7. Ghoniem G, Corcos J, Comiter C, Bernhard P, Westney OL, Herschorn S: Cross-linked polydimethylsiloxane injection for female stress urinary incontinence: results of a multicenter, randomized, controlled, single-blind study. J Urol 2009, | 8 1:204- 10.

8. Tamanini JT, D'Ancona CA, Netto NR: Macroplastique implantation system for female stress urinary incontinence: long-term follow-up. J Endourol 2006, 20:1082-6.

9. Zullo MA, Plotti F, Calcagno M, Angioli R, Panici PB: Transurethral polydimethylsiloxane injection: a valid minimally invasive option for the treatment of postradical hysterectomy urinary incontinence. J Minim Invasive Gynecol 2008, I 5:373-6.

10. Tamussino K, Hanzal E, Kölle D, Tammaa A, Preyer O, Umek W, Bjelic-Radisic V, Enzelsberger H, Lang PF, Ralph G, Riss P; Austrian Urogynecology Working Group: Transobturator tapes for stress urinary incontinence: results of the Austrian registry. Am J Obstet Gynecol 2007, 197:634.el-5.

II. Ammendrup AC, Bendixen A, Sander P, Ottesen BS, Lose G: [Urinary incontinence surgery in Denmark 200I-2003] [article in Danish]. Ugeskr Laeger 2009, I 7 I:399-404.

12. Basu M, Duckett J: A randomised trial of the surgical treatment of urodynamic stress incontinence - the TVT versus MiniArc. Int Urogynecol J Pelvic Floor Dysfunct 2009, 20(Suppl 2):S74. Abstract 003.

13. Amat L, Tardiu I, Martinez Franco E, Pere Cruz M, Valladares Perez E, Lailla Vicens J: Randomized controlled trial compared TVT-O ${ }^{\circledR}$ 
versus Contasure Needleless ${ }^{\circledR}$. One year follow-up results. Int Urogynecol J Pelvic Floor Dysfunct 2009, 20(Suppl 2):SI27. Abstract 06I.

14. National Institute for Health and Clinical Excellence: Singleincision sub-urethral short tape insertion for stress urinary incontinence in women. May 2008. [http://www.nice.org.uk/ nicemedia/pdf/IPG262Guidance.pdf].

15. Schraffordt Koops SE, Bisseling TM, van Brummen HJ, Heintz AP, Vervest HA: Result of the tension-free vaginal tape in patients with concomitant prolapse surgery: a 2-year follow-up study. An analysis from the Netherlands TVT database. Int Urogynecol J Pelvic Floor Dysfunct 2007, 18:437-42.

16. Anger JT, Litwin MS, Wang Q, Pashos CL, Rodríguez LV: The effect of concomitant prolapse repair on slig outcomes. J Urol 2008, 180:1003-6.

FI000 Factor 6.0 Must Read

Evaluated by Bassem Wadie 05 Jan 2009

17. Fourth International Consultation On Incontinence (ICI) Management Using Continence Products Committee Highlights. [http://www.medicalnewstoday.com/articles/I 16I23.php].

18. Ballert KN, Biggs GY, Isenalumhe A Jr, Rosenblum N, Nitti VW: Managing the urethra at transvaginal pelvic organ prolapse repair: a urodynamic approach. J Urol 2009, 181:679-84.

FI000 Factor 3.0 Recommended

Evaluated by Eric Rovner 28 Apr 2009

19. Araco F, Gravante G, Sorge R, Overton J, De Vita D, Sesti F, Piccione E: TVT-O vs TVT: a randomized trial in patients with different degrees of urinary stress incontinence. Int Urogynecol J Pelvic Floor Dysfunct 2008, 19:917-26.

20. Foon R, Toozs-Hobson P, Latthe PM: Adjuvant materials in anterior vaginal wall prolapse surgery: a systematic review of effectiveness and complications. Int Urogynecol J Pelvic Floor Dysfunct 2008, 19:1697-706.

21. Natale F, La Penna C, Padoa A, Agostini M, De Simone E, Cervigni M: A prospective, randomized, controlled study comparing Gynemesh, a synthetic mesh, and Pelvicol, a biologic graft, in the surgical treatment of recurrent cystocele. Int Urogynecol] Pelvic Floor Dysfunct 2009, 20:75-8I.

22. Handel LN, Frenkl TL, Kim YH: Results of cystocele repair: a comparison of traditional anterior colporrhaphy, polypropylene mesh and porcine dermis. J Urol 2007, I78: I53-6; discussion 156.

23. Ganj FA, Ibeanu OA, Bedestani A, Nolan TE, Chesson RR: Complications of transvaginal monofilament polypropylene mesh in pelvic organ prolapse repair. Int Urogynecol J Pelvic Floor Dysfunct 2009, 20:919-25.

24. Nguyen JN, Burchette RJ: Outcome after anterior vaginal prolapse repair: a randomized controlled trial. Obstet Gynecol 2008, I I I:89|-8.

25. Ross JW: Porcine dermal hammock for repair of anterior and posterior vaginal wall prolapse: 5-year outcome. J Minim Invasive Gynecol 2008, 15:459-65.

26. Abdel-Fattah M, Ramsay I; West of Scotland Study Group: Retrospective multicentre study of the new minimally invasive mesh repair devices for pelvic organ prolapse. BJOG 2008, I I5:22-30.

27. Manufacturer and User Facility Device Experience Database (MAUDE). [http://www.fda.gov/MedicalDevices/DeviceRegulationandGuidance/PostmarketRequirements/ReportingAdverseEvents/ ucm I 2789I.htm].

28. Caquant $F$, Collinet $P$, Debodinance $P$, Berrocal J, Garbin $O$, Rosenthal C, Clave H, Villet R, Jacquetin B, Cosson M: Safety of Trans Vaginal Mesh procedure: retrospective study of 684 patients. J Obstet Gynaecol Res 2008, 34:449-56.

29. US Food and Drug Administration - FDA Public Health Notification: Serious Complications Associated with Transvaginal Placement of Surgical Mesh in Repair of Pelvic Organ Prolapse and Stress Urinary Incontinence. [http://www.fda.gov/ MedicalDevices/Safety/AlertsandNotices/PublicHealthNotifications/ ucm06 1976.htm].

30. Altman D, Falconer C: Perioperative morbidity using transvaginal mesh in pelvic organ prolapse repair. Obstet Gynecol 2007 109:303-8.

FI000 Factor 6.0 Must Read Evaluated by Linda Brubaker 02 May 2007

31. Deffieux X, Desseaux K, de Tayrac R, Faivre E, Frydman R, Fernandez H: Infracoccygeal sacropexy for uterovaginal prolapse. Int J Gynaecol Obstet 2009, I04:56-9.

FI000 Factor 6.0 Must Read

Evaluated by Joan Pitkin 13 May 2009

32. Gonzalez R, Fugate K, McClusky D 3rd, Ritter EM, Lederman A, Dillehay D, Smith CD, Ramshaw BJ: Relationship between tissue ingrowth and mesh contraction. World J Surg 2005, 29: 1038-43.

33. Sergent F, Desilles N, Lacoume Y, Bunel C, Marie JP, Marpeau L: Experimental biomechanical evaluation of polypropylene prostheses used in pelvic organ prolapse surgery. Int Urogynecol J Pelvic Floor Dysfunct 2009, [Epub ahead of print]. 